\title{
EFicÁcia de Herbicidas Aplicados nas Épocas SeCa e Úmida PaRa o Controle DE Merremia aegyptia NA CULTURA DA CANA-DE-AçÚCAR ${ }^{1}$
}

\author{
Efficacy of Herbicides Applied During the Dry and Wet Seasons for the Control of \\ Merremia aegyptia in Sugarcane
}

\author{
CORREIA, N.M. ${ }^{2}$, BRAZ, B.A. ${ }^{3}$ e FUZITA, W.E. ${ }^{4}$
}

\begin{abstract}
RESUMO - Objetivou-se estudar o efeito de herbicidas aplicados em pré e pós-emergência, isolados e em combinações nas épocas seca e úmida, para o controle de corda-de-viola (Merremia aegyptia) na cultura de cana-de-açúcar colhida mecanicamente sem queima. $\mathrm{O}$ experimento foi desenvolvido no período de julho de 2008 a maio de 2009 , em área de produção comercial de cana-de-açúcar localizada no município de Pradópolis, SP. O delineamento experimental foi o de blocos ao acaso, com quatro repetições, em esquema de parcela subdividida. Foram avaliados na época seca os herbicidas amicarbazone (1.400 g ha ${ }^{1}$ ), clomazone + hexazinone $\left(800+200 \mathrm{~g} \mathrm{ha}^{-1}\right)$ e imazapic $\left(147 \mathrm{~g} \mathrm{ha}^{-1}\right)$, aplicados em 16/7/2008 após a colheita da cana, e o tratamento sem manejo prévio das plantas daninhas nessa época. Os herbicidas estudados na época úmida foram: mesotrione isolado (192 $\left.\mathrm{g} \mathrm{ha}{ }^{-1}\right) \mathrm{e} \mathrm{em}$ mistura (120 $\left.\mathrm{g} \mathrm{ha}^{-1}\right)$ com atrazine $\left(1.500 \mathrm{~g} \mathrm{ha}^{-1}\right)$, metribuzin $\left(960 \mathrm{~g} \mathrm{ha}^{-1}\right)$ ou diuron thexazinone $\left(702+198 \mathrm{~g} \mathrm{ha}^{-1}\right)$, aplicados em $6 / 11 / 2008$, além de testemunha capinada e outra sem manejo das plantas daninhas. Dos herbicidas utilizados na época seca, o amicarbazone promoveu o melhor controle de $M$. aegyptia. No entanto, para todos eles, a complementação de manejo com a aplicação de herbicidas na época úmida mostrou-se obrigatória. Nesta época, a associação de mesotrione aos herbicidas atrazine, metribuzin e diuron + hexazinone foi mais eficaz no controle de $M$. aegyptia do que quando aplicado sozinho. Nenhum dos tratamentos com herbicidas interferiu no número de colmos por metro linear, diâmetro e altura de colmos de cana-de-açúcar (variedade SP 81-3250).
\end{abstract}

Palavras-chave: corda-de-viola, planta daninha, Saccharum spp.

\begin{abstract}
To evaluate the efficacy of herbicides applied in pre and post-emergence, alone and in combination, during the dry and wet seasons, for the control of hairy woodrose (Merremia aegyptia) on sugarcane, an experiment was arranged in a randomized block design, in split-plots, with four replications, in a commercial production area in Pradópolis, São Paulo, Brazil, from July 2008 to May 2009. Three herbicide treatments [amicarbazone $\left(1.4 \mathrm{~kg} \mathrm{ha}^{-1}\right)$, imazapic $\left(0.147 \mathrm{~kg} \mathrm{ha}{ }^{-1}\right)$ and clomazone plus hexazinone $\left(0.8 \mathrm{~kg} \mathrm{ha} a^{-1}\right.$ plus $\left.0.2 \mathrm{~kg} \mathrm{ha}^{-1}\right)$ applied on July 16,2008, after sugarcane harvest, and one treatment without herbicide were tested. To evaluate the need of herbicide application during the wet season, the combinations of four extra herbicide treatments and two treatments without herbicides were studied. The herbicides used at the second experimental stage were: mesotrione alone $\left(0.192 \mathrm{~kg} \mathrm{ha} \mathrm{h}^{-1}\right)$, and in mixture $\left(0.12 \mathrm{~kg} \mathrm{ha}^{-1}\right)$ with atrazine $\left(1.5 \mathrm{~kg} \mathrm{ha} \mathrm{a}^{-1}\right)$, metribuzin $\left(0.96 \mathrm{~kg} \mathrm{ha} \mathrm{h}^{-1}\right)$ or diuron plus hexazinone $\left(0.702\right.$ plus $\left.0.198 \mathrm{~kg} \mathrm{ha} \mathrm{a}^{-1}\right)$, applied in post-emergence on November 6, 2008. Amicarbazone presented the best M. aegyptia control among the herbicides applied during the dry season. However, anagement complementation with herbicide application during the wet season was found to be mandatory for all herbicides. In the second experimental stage, the association of mesotrione to atrazine, metribuzin and diuron plus hexazinone was more efficient for M. aegyptia control than when applied alone. None of the herbicide treatments affect stalk number, stalk diameter and stalk height in sugarcane (variety SP 81-3250).
\end{abstract}

Keywords: hairy woodrose, weed, Saccharum spp.

Recebido para publicação em 18.8.2009 e na forma revisada em 3.9.2010.

2 Professor, Dr., Dep. de Fitossanidade da Universidade Estadual Paulista - UNESP, Campus de Jaboticabal, Via de Acesso Prof. Paulo Donato Castellane, s/n, 14884-900 Jaboticabal-SP, Brasil, <correianm@fcav.unesp.br>; ${ }^{3}$ Syngenta Proteção de Cultivos Ltda., Jaboticabal-SP; ${ }^{4}$ Syngenta Proteção de Cultivos Ltda., Maringá-PR. 


\section{INTRODUÇÃO}

Nas regiões Sudeste e Centro-Oeste do Brasil a colheita de cana-de-açúcar inicia-se nos meses de abril/maio, estendendo-se até novembro/dezembro do ano agrícola. Após o corte são realizados os tratos culturais necessários para a brotação e o crescimento das plantas, incluindo o manejo de plantas daninhas. Nas épocas mais secas do ano (junho, julho e agosto) a aplicação de herbicidas pode ser realizada em pré-emergência, após a colheita, ou em pós-emergência, quando a umidade do solo for restabelecida. No entanto, para utilização na época seca os herbicidas devem apresentar alta solubilidade em água e fraca ou moderada adsorção ao solo. Assim, mesmo numa condição de baixa umidade no solo, parte do produto será dessorvida para a solução e estará disponivel para absorção pela radícula e/ou caulículo das plântulas. Entre os herbicidas registrados para a cultura de canade-açúcar, apenas amicarbazone, imazapic, hexazinone, isoxaflutole, sulfentrazone e tebuthiuron são recomendados para o uso na época seca, além da mistura comercial de clomazone + hexazinone (Procópio et al., 2008; Rodrigues \& Almeida, 2005; Agrofit, 2010).

Por outro lado, adaptados à aplicação de herbicidas na época seca, tanto as usinas como os seus fornecedores depararam-se com algumas adversidades no controle de plantas daninhas nos últimos anos: primeiramente a palha, oriunda do corte sem queima da canade-açúcar, associada à aplicação de herbicidas residuais em pré-emergência e, posteriormente, o aumento da infestação de espécies de trepadeiras, como as dos gêneros Merremia e Ipomoea, nas áreas. Possivelmente, a manutenção da palha de cana na superfície do solo cria ambiente mais favorável à germinação das sementes e ao desenvolvimento das plantas, devido à menor amplitude térmica diária, maior conservação da umidade do solo e melhoria química e física deste. Correia \& Durigan (2004) relataram que a emergência de Ipomoea grandifolia, I. hederifolia e I. quamoclit não foi influenciada pelos níveis de palha estudados $\left(5,10\right.$ e $\left.15 \mathrm{t} \mathrm{ha}^{-1}\right)$. Pelo contrário, na presença de cobertura morta sob o solo, houve aumento no número de plântulas emergidas e no acúmulo de matéria seca das plantas de I. quamoclit, comparado ao tratamento sem palha.
Cerca de $74 \%$ das espécies dos gêneros Ipomoea e Merremia da região Sudeste do Brasil são trepadeiras, apresentando caules e ramos volúveis que se entrelaçam em plantas vizinhas ou crescem sobre obstáculos (Kissmann $\&$ Groth, 1999). Além dos prejuízos ocasionados pela competição por água, luz, nutrientes e espaço, essas espécies causam sérios danos à cana-de-açúcar no momento da colheita, pois dificultam a colheita mecanizada, comprometendo o rendimento das máquinas e a qualidade do produto colhido.

No trabalho sobre fitossociologia de comunidades infestantes em 28 agroecossistemas de cana colhida mecanicamente sem queima (cana-crua), Kuva et al. (2007) mencionaram que as espécies I. nil, I. quamoclit, I. hederifolia, I. grandifolia, I. purpurea e $M$. cissoides destacaram-se em 17 áreas. Portanto, os herbicidas ou métodos de controle utilizados em cana-crua deverão apresentar, além de capacidade da transpor a palha, eficácia no controle de diversas espécies dos gêneros Ipomoea e Merremia (Kuva et al., 2007).

A dificuldade de manejo dessas espécies não está na redução da mortalidade da planta ou da plântula tratada, mas na inibição dos novos fluxos de emergência das plantas daninhas. As infestações tardias, fora do período crítico de prevenção da interferência, podem comprometer a colheita mecanizada da cana. Enfim, o agroecossistema da cana mudou, porém o manejo das plantas daninhas não acompanhou a mudança. As práticas agrícolas continuam as mesmas adotadas para cana sem palha e com queima. Contudo, as dúvidas permanecem, como o controle de infestações futuras de Ipomoea e Merremia por herbicidas aplicados na época seca, mesmo após quatro, cinco ou até seis meses da aplicação; a necessidade (ou não) de uma nova aplicação na época úmida; a importância dessas duas épocas de aplicação no manejo de espécies de Ipomoea e Merremia, entre outras.

Com a hipótese de que o uso de herbicidas na época seca deve ser complementado com a aplicação daqueles de ação residual na época úmida, objetivou-se estudar o efeito de herbicidas aplicados em pré e pós-emergência, isolados e em combinações nas épocas seca e úmida, para o controle de $M$. aegyptia na cultura da cana-de-açúcar colhida 
mecanicamente sem queima prévia das plantas.

\section{MATERIAL E MÉTODOS}

O experimento foi desenvolvido no período de julho de 2008 a maio de 2009, em área de produção comercial de cana-de-açúcar localizada no município de Pradópolis, SP.

O delineamento experimental foi o de blocos ao acaso, com quatro repetições, em esquema de parcela subdividida. Nas parcelas foram estudados três herbicidas (pulverizados na época seca), além de tratamento sem aplicação, e, nas subparcelas, as aplicações (em pós-emergência) de quatro herbicidas na época úmida e duas testemunhas sem herbicida: uma com a eliminação manual das plantas daninhas (testemunha capinada) e outra sem manejo químico ou manual (testemunha sem manejo).

$\mathrm{Na}$ época seca foram avaliados os herbicidas amicarbazone ( $\left.1.400 \mathrm{~g} \mathrm{ha}^{-1}\right)$, clomazone + hexazinone $\left(800+200 \mathrm{~g} \mathrm{ha}^{-1}\right)$ e imazapic (147 $\mathrm{g} \mathrm{ha}^{-1}$ ), aplicados em pré-emergência após a colheita da cana. Os herbicidas estudados na época úmida foram: mesotrione isolado (192 $\mathrm{g} \mathrm{ha}^{-1}$ ) e em mistura (120 $\left.\mathrm{g} \mathrm{ha}^{-1}\right)$ com atrazine (1.500 $\left.\mathrm{g} \mathrm{ha}^{-1}\right)$, metribuzin (960 $\left.\mathrm{g} \mathrm{ha}^{-1}\right)$ ou diuron + hexazinone $\left(702+198 \mathrm{~g} \mathrm{ha}^{-1}\right)$. Em todas as caldas de mesotrione adicionou-se óleo mineral a $0,5 \% \mathrm{v} \mathrm{v}^{-1}$.

Cada parcela foi constituída de $6,0 \mathrm{~m}$ de largura (quatro linhas de cana) e $36,0 \mathrm{~m}$ de comprimento, totalizando $216,0 \mathrm{~m}^{2}$. Dentro delas, foram demarcadas as subparcelas, com 6,0 m de largura e 6,0 m de comprimento.

A variedade de cana-de-açúcar SP 81-3250, no seu primeiro corte, foi colhida mecanicamente no dia 15 de julho de 2008, com a manutenção de $8,5 \mathrm{t}^{\text {ha }}{ }^{-1}$ de palha sobre o solo.

$\mathrm{Na}$ época seca, os herbicidas foram aplicados em 16/7/2008 com o auxilio de um pulverizador costal, à pressão constante (mantida por $\mathrm{CO}_{2}$ comprimido) de $3,0 \mathrm{kgf} \mathrm{cm}^{-2}$, munido de barra com seis pontas de pulverização de jato plano XR 11002, espaçadas de $0,5 \mathrm{~m}$, com consumo de calda equivalente a $200 \mathrm{~L} \mathrm{ha}^{-1}$. Na época úmida, a aplicação foi realizada em 6/11/2008, 113 dias após o corte da cana e com $6,43 \mathrm{t} \mathrm{ha}^{-1}$ sobre o solo.
Devido ao porte da cana, a pulverização foi dirigida, localizada na entrelinha da cultura, procurando-se atingir unicamente as plantas daninhas, sem a ocorrência de possivel efeito "guarda-chuva" das plantas de cana. Dessa forma, foi utilizado pulverizador costal, à pressão constante (mantida pelo $\mathrm{CO}_{2}$ comprimido) de 4,0 $\mathrm{kgf} \mathrm{cm}^{-2}$, munido de barra com duas pontas de pulverização de jato plano TT 11002 , espaçadas de $0,75 \mathrm{~m}$, com consumo de calda equivalente a $200 \mathrm{~L} \mathrm{ha}^{-1}$. No momento das aplicações, foram registrados os valores de temperatura do ar, umidade relativa do ar e velocidade dos ventos (Tabela 1 ).

Na segunda aplicação, as plantas de cana encontravam-se com $85 \mathrm{~cm}$ de altura média do dosse1, e as de $M$. aegypitia, do estágio cotiledonar a plantas adultas de 20 a $90 \mathrm{~cm}$ de altura. A comunidade infestante da área experimental foi composta unicamente por M. aegyptia.

Na Tabela 2 são apresentados o número médio de folhas por planta, a altura média de plantas, a porcentagem média de cobertura do solo e a densidade média de plantas de $M$. aegyptia para cada manejo adotado na época seca.

Aos 7, 15 e 30 dias após a aplicação dos herbicidas na época seca $\left(\mathrm{DAA}_{\mathrm{HS}}\right)$ foram avaliados possiveis sintomas visuais de intoxicação nas plantas de cana, por meio da escala de notas de 0 a $100 \%$, em que 0 representa a ausência de injúrias visuais e 100 a morte de todas as plantas (SBCDP, 1995).

Aos 7, 15, 29, 46, 60, 75, 90, 107 e $114 \mathrm{DAA}_{\mathrm{HS}}$ foi realizada a contagem do número de plantas emergidas de $M$. aegyptia em 12 pontos de $1,0 \mathrm{~m}^{2}$ cada, escolhidos aleatoriamente dentro da área útil de cada parcela $\left(105,0 \mathrm{~m}^{2}\right)$.

Aos 15, 30, 62, 91 e 120 dias após a aplicação dos herbicidas na época úmida $\left(\mathrm{DAA}_{\mathrm{HU}}\right)$ foram realizadas avaliações visuais de controle de $M$. aegyptia, utilizando-se escala de notas de 0 a $100 \%$. Aos 8, 15 e $30 \mathrm{DAA}_{\mathrm{HU}}$ foram avaliados possiveis sintomas visuais de intoxicação nas plantas de cana, atribuindo-se notas em porcentagens.

As notas de controle foram estabelecidas em função do tratamento mantido infestado 
Tabela 1 - Temperatura do ar, umidade relativa do ar e velocidade do vento no início e final das aplicações dos herbicidas, além das datas e horários das pulverizações e umidade do solo. Pradópolis-SP. 2008/09

\begin{tabular}{|l|c|c|c|c|c|c|}
\hline \multicolumn{1}{|c|}{ Aplicação } & Data & Horário & $\begin{array}{c}\text { Temperatura } \\
\left({ }^{\circ} \mathrm{C}\right)\end{array}$ & $\begin{array}{c}\text { Umidade do ar } \\
(\%)\end{array}$ & $\begin{array}{c}\text { Vento } \\
\left(\mathrm{km} \mathrm{h}^{-1}\right)\end{array}$ & Umidade do solo \\
\hline Época seca & $16 / 07 / 2008$ & $9 \mathrm{~h} 45-10 \mathrm{~h} 45$ & $20,3-22,3$ & $51-48$ & $1,5-5,1$ & Seco \\
\hline Época úmida & $06 / 11 / 2008$ & $9 \mathrm{~h} 30-12 \mathrm{~h} 30$ & $28,3-35,0$ & $63-40$ & $2,4-5,7$ & Úmido \\
\hline
\end{tabular}

Tabela 2 - Número de folhas por planta, altura média de plantas, porcentagem média de cobertura do solo e densidade média de plantas por $\mathrm{m}^{2}$ de Merremia aegyptia no momento da aplicação dos herbicidas na época úmida, para cada manejo adotado na seca. Pradópolis-SP. 2008/09

\begin{tabular}{|l|c|c|c|c|}
\hline \multicolumn{1}{|c|}{ Manejo na época seca } & $\begin{array}{c}\text { Número de } \\
\text { folhas/planta }\end{array}$ & $\begin{array}{c}\text { Altura } \\
(\mathrm{cm})\end{array}$ & $\begin{array}{c}\text { Cobertura } \\
(\%)\end{array}$ & $\begin{array}{c}\text { Densidade } \\
\left(\text { plantas }^{-2}\right)\end{array}$ \\
\hline amicarbazone & cotiledonares a 2 & 4,00 & 5,00 & 1,97 \\
\hline clomazone+hexazinone & cotiledonares a 7 & 11,00 & 15,00 & 3,49 \\
\hline imazapic & cotiledonares a 7 & 23,00 & 17,50 & 5,12 \\
\hline Tratamento sem herbicida & cotiledonares a 8 & 34,75 & 60,00 & 14,20 \\
\hline
\end{tabular}

durante todo o período experimental, representado pela subparcela sem aplicação de herbicida nas épocas seca e úmida.

Aos 15, 30, 45 e $62 \mathrm{DAA}_{\mathrm{HU}}$ foi realizada a contagem do número de plantas de $M$. aegyptia emergidas em quatro pontos de $0,45 \mathrm{~m}^{2}$ cada, escolhidos aleatoriamente dentro da área útil de cada subparcela $\left(15,0 \mathrm{~m}^{2}\right)$.

Aos 313 dias após a colheita da cana, foi realizada a contagem do número de colmos viáveis em quatro metros lineares e a medição da altura e do diâmetro de 10 colmos de cana escolhidos dentro da área útil de cada subparcela. A dificuldade de colheita mecanizada dos colmos de cana também foi avaliada por meio de escala de notas de 1 a 3 . As notas representavam: 1 - colheita sem $M$. aegyptia ou com baixa infestação (sem causar impedimentos), 2 - colheita com presença moderada de $M$. aegyptia e 3 - colheita com presença elevada de $M$. aegyptia.

Os resultados obtidos foram submetidos à análise de variância, empregando-se o teste $\mathrm{F}$, e as médias comparadas pelo teste de Tukey a $5 \%$ de probabilidade. Os dados referentes ao número de plantas de $M$. aegyptia avaliadas na época seca, às notas de fitointoxicação (nas duas épocas de aplicação) e às notas de dificuldade de colheita não foram submetidos à análise estatística.

\section{RESULTADOS E DISCUSSÃO}

\section{Etapa: manejo de Merremia aegyptia na época seca}

$\mathrm{Na}$ época seca foram observados picos de emergência de $M$. aegyptia nas parcelas em resposta à disponibilidade de água no solo, de acordo com os indices pluviométricos registrados no período (Figuras 1 e 2). Em todas as épocas de avaliação houve maior número de plântulas no tratamento sem herbicida, com 14,2 plantas $\mathrm{m}^{-2}$ em $7 / 11 / 2008$, seguido de imazapic $\left(5,12\right.$ plantas $\left.\mathrm{m}^{-2}\right)$, clomazone + hexazinone $\left(3,49\right.$ plantas $\left.\mathrm{m}^{-2}\right)$ e amicarbazone $\left(1,97\right.$ plantas $\left.\mathrm{m}^{-2}\right)$. Além das diferenças na densidade de plantas de $M$. aegyptia, os tratamentos também diferiram quanto a número de folhas, altura e porcentagem de infestação. Nas parcelas pulverizadas com amicarbazone havia apenas plântulas de $M$. aegyptia com até duas folhas definitivas e altura média de 4,0 $\mathrm{cm}$, ocupando apenas 5,0\% da área (Tabela 2), contrariamente aos demais tratamentos de seca, que resultaram em plantas de maior altura e porcentagem de cobertura, principalmente no tratamento sem herbicida, em que as plantas de $M$. aegyptia apresentaram altura média de $34,75 \mathrm{~cm}$ e $60 \%$ de cobertura do solo. 


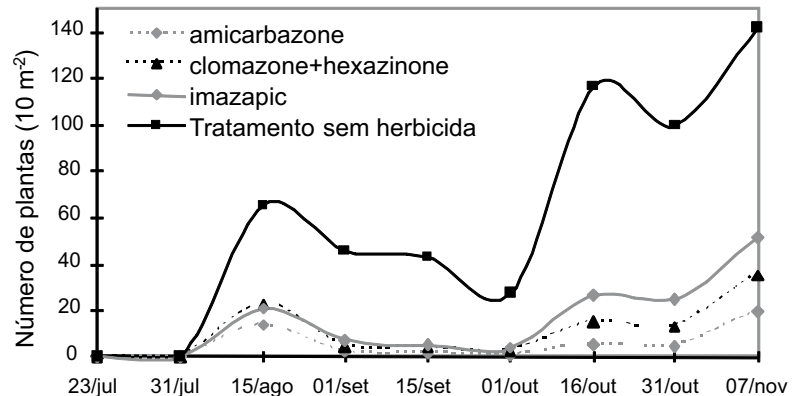

Figura 1 - Dinâmica da emergência de Merremia aegyptia após a aplicação de amicarbazone, clomazone + hexazinone e imazapic, no dia 16 de julho de 2008, além do tratamento sem manejo prévio da planta daninha na época seca. Pradópolis-SP. 2008/09.

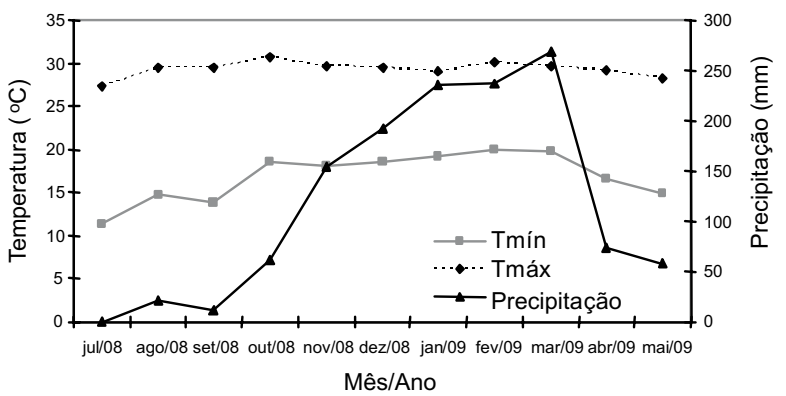

Figura 2 - Precipitação e temperaturas do ar mínima e máxima registradas no período de julho de 2008 a junho de 2009, em estação agroclimatológica localizada a $6 \mathrm{~km}$ do experimento. Pradópolis-SP. 2008/2009.

Os herbicidas amicarbazone e imazapic não causaram nenhum dano visivel às plantas de cana ( $0 \%$ de fitointoxicação), enquanto clomazone + hexazinone proporcionaram sintomas moderados de fitointoxicação (média de $15 \%$ ), que diminuíram ao longo do tempo (dados não apresentados). Aos 30 DAA não foram mais observados danos visuais, resultado da recuperação das plantas.

\section{2․ Etapa: manejo de Merremia aegyptia na época úmida}

A interação manejo na época seca $x$ manejo na época úmida foi significativa para todas as épocas de avaliação visual de controle. Aos $15 \mathrm{DAA}_{\mathrm{HU}}$, para os herbicidas amicarbazone e clomazone + hexazinone, não houve diferença estatística entre os herbicidas aplicados na época úmida, porém todos eles diferiram da testemunha sem manejo nessa época (Tabela 3). Para imazapic e tratamento sem herbicida na época seca, o mesotrione associado aos herbicidas atrazine, metribuzin e diuron + hexazinone ocasionou as maiores porcentagens de controle do que quando aplicado sozinho. Sem a aplicação de herbicidas na época úmida (testemunha sem manejo), as maiores notas de controle foram obtidas com a pulverização de amicarbazone e clomazone + hexazinone $(78,75$ e $71,75 \%$, respectivamente), diferindo de imazapic e tratamento sem herbicida na seca.

As notas de controle decresceram a partir dos $30 \mathrm{DAA}_{\mathrm{HU}}$ como resultado da emergência de novas plântulas de $M$. aegyptia nas parcelas (Tabela 4). Nessa época de avaliação, quando foi aplicado amicarbazone na seca os manejos adotados na época úmida não diferiram entre si, ou seja, os tratamentos de herbicidas resultaram em controle estatisticamente similar ao das testemunhas (capinada e sem manejo). Nas parcelas pulverizadas com imazapic e clomazone + hexazinone não houve diferença significativa entre a aplicação isolada e em mistura de mesotrione, diferindo apenas da testemunha sem manejo. Sem a aplicação de herbicida na época seca, os melhores resultados de controle foram obtidos com as associações de mesotrione aos herbicidas atrazine, metribuzin ou diuron + hexazinone.

Quando não foi realizada a complementação de manejo químico de $M$. aegyptia na época úmida (testemunha sem manejo), o herbicida amicarbazone proporcionou as maiores porcentagens de controle, diferindo de todos os outros tratamentos avaliados na época seca.

Aos $62 \mathrm{DAA}_{\mathrm{HU}}$, para amicarbazone, imazapic e tratamento sem herbicida na seca, os melhores resultados de controle de M. aegyptia foram obtidos com as associações de mesotrione ao atrazine, metribuzin ou diuron + hexazinone (Tabela 5). Quando foi utilizado clomazone + hexazinone na época seca, não houve diferença estatística entre a aplicação de mesotrione isolado e em mistura com atrazine, metribuzin ou diuron + hexazinone. Nas parcelas de amicarbazone, sem a complementação de manejo na época úmida, houve melhor controle $(60 \%)$ da planta daninha, comparado aos outros manejos adotados na época seca. 
Tabela 3 - Porcentagem de controle de Merremia aegyptia aos 15 dias após a aplicação de herbicidas na época úmida. Pradópolis-SP. 2008/2009

\begin{tabular}{|c|c|c|c|c|}
\hline \multirow[b]{2}{*}{ Manejo na época úmida } & \multicolumn{4}{|c|}{ Manejo na época seca } \\
\hline & amicarbazone & $\begin{array}{l}\text { clomazone }+ \\
\text { hexazinone }\end{array}$ & imazapic & $\begin{array}{c}\text { Tratamento sem } \\
\text { herbicida }\end{array}$ \\
\hline mesotrione & $93,75 \mathrm{a} \mathrm{A}^{\mathrm{1}^{\prime}}$ & $91,25 \mathrm{a} A B$ & 83,75 b BC & $77,50 \mathrm{~b} \mathrm{C}$ \\
\hline mesotrione + atrazine & $100,00 \mathrm{a} \mathrm{A}$ & 100,00 a A & 97,50 a $\mathrm{A}$ & 100,00 a A \\
\hline mesotrione + metribuzin & 100,00 a A & 98,75 a A & 97,50 a $\mathrm{A}$ & 98,75 a A \\
\hline mes.+(diuron+hexazinone) & 100,00 a $\mathrm{A}$ & 100,00 a $\mathrm{A}$ & 100,00 a $\mathrm{A}$ & 100,00 a $\mathrm{A}$ \\
\hline Testemunha capinada ${ }^{2 / /}$ & 100,00 a A & 100,00 a A & 100,00 a A & 100,00 a A \\
\hline Testemunha sem manejo & $78,75 \mathrm{~b} \mathrm{~A}$ & $71,25 \mathrm{~b} \mathrm{~A}$ & $45,00 \mathrm{c} \mathrm{B}$ & $0,00 \mathrm{c} \mathrm{C}$ \\
\hline DMS (linha) & \multicolumn{4}{|c|}{9,54} \\
\hline DMS (coluna) & \multicolumn{4}{|c|}{10.41} \\
\hline
\end{tabular}

${ }^{1 /}$ Com base no teste de Tukey a 5\% de probabilidade, médias seguidas de letra minúscula, nas colunas, comparam os tratamentos da época úmida dentro de cada manejo na época seca, e letras maiúsculas, nas linhas, comparam os quatro manejos na seca para cada tratamento da época úmida. 르 Testemunha capinada apenas no dia da pulverização dos herbicidas na época úmida.

Tabela 4 - Porcentagem de controle de Merremia aegyptia aos 30 dias após a aplicação de herbicidas na época úmida. Pradópolis-SP. 2008/2009

\begin{tabular}{|c|c|c|c|c|}
\hline \multirow[b]{2}{*}{ Manejo na época úmida } & \multicolumn{4}{|c|}{ Manejo na época seca } \\
\hline & amicarbazone & $\begin{array}{l}\text { clomazone + } \\
\text { hexazinone }\end{array}$ & imazapic & $\begin{array}{c}\text { Tratamento sem } \\
\text { herbicida }\end{array}$ \\
\hline mesotrione & $91,25 \mathrm{a} \mathrm{A}^{1 / /}$ & 86,25 a $\mathrm{AB}$ & $79,25 \mathrm{a} \mathrm{AB}$ & $66,25 \mathrm{~b} \quad \mathrm{~B}$ \\
\hline mesotrione + atrazine & 98,00 a A & 97,75 a A & $94,25 \mathrm{a} \mathrm{A}$ & $96,25 \mathrm{a} \quad \mathrm{A}$ \\
\hline mesotrione + metribuzin & 98,75 a A & 97,25 a $\mathrm{A}$ & 94,75 a A & $93,75 \mathrm{a} \quad \mathrm{A}$ \\
\hline mes.+(diuron+hexazinone) & 99,25 a A & 93,50 a $\mathrm{A}$ & 97,50 a $\mathrm{A}$ & $96,25 \mathrm{a} \quad \mathrm{A}$ \\
\hline Testemunha capinada $^{2 /}$ & 97,50 a $\mathrm{A}$ & 86,25 a $A$ & 88,50 a $\mathrm{A}$ & $76,25 \mathrm{ab} \mathrm{A}$ \\
\hline Testemunha sem manejo & $80,50 \mathrm{a} \mathrm{A}$ & $58,75 \mathrm{~b} \mathrm{~B}$ & $31,25 \mathrm{~b} \mathrm{C}$ & $0,00 \mathrm{c} \quad \mathrm{D}$ \\
\hline DMS (linha) & \multicolumn{4}{|c|}{21,48} \\
\hline DMS (coluna) & \multicolumn{4}{|c|}{22,17} \\
\hline
\end{tabular}

${ }^{1 /}$ Com base no teste de Tukey a $5 \%$ de probabilidade, médias seguidas de letra minúscula, nas colunas, comparam os tratamentos da época úmida dentro de cada manejo na época seca, e letras maiúsculas, nas linhas, comparam os quatro manejos na seca para cada tratamento da época úmida. ${ }^{2 /}$ Testemunha capinada apenas no dia da pulverização dos herbicidas na época úmida.

Tabela 5 - Porcentagem de controle de Merremia aegyptia aos 62 dias após a aplicação de herbicidas na época úmida. Pradópolis-SP. $2008 / 2009$

\begin{tabular}{|c|c|c|c|c|}
\hline \multirow[b]{2}{*}{ Manejo na época úmida } & \multicolumn{4}{|c|}{ Manejo na época seca } \\
\hline & amicarbazone & $\begin{array}{l}\text { clomazone + } \\
\text { hexazinone }\end{array}$ & imazapic & $\begin{array}{c}\text { Tratamento sem } \\
\text { herbicida }\end{array}$ \\
\hline mesotrione & $82,50 \mathrm{ab} \mathrm{A}^{\underline{1 /}}$ & 72,50 a A & 43,75 b B & $26,25 \mathrm{~b} \mathrm{~B}$ \\
\hline mesotrione + atrazine & 88,75 a $\mathrm{A}$ & 83,75 a A & 76,25 a A & 76,25 a A \\
\hline mesotrione + metribuzin & $86,25 \mathrm{a} \quad \mathrm{A}$ & 83,75 a A & 81,25 a A & 73,75 a A \\
\hline mes.+(diuron+hexazinone) & $92,50 \mathrm{a} \quad \mathrm{A}$ & 75,00 a $\mathrm{A}$ & $80,00 \mathrm{a} \mathrm{A}$ & 75,00 a $\mathrm{A}$ \\
\hline Testemunha capinada ${ }^{2 /}$ & $83,75 \mathrm{ab} A$ & 66,25 a A & 68,75 a $\mathrm{A}$ & $41,25 \mathrm{~b} \mathrm{~B}$ \\
\hline Testemunha sem manejo & $60,00 \mathrm{~b} A$ & $33,75 \mathrm{~b} \mathrm{~B}$ & $0,00 \mathrm{c} \mathrm{C}$ & $0,00 \mathrm{c} \mathrm{C}$ \\
\hline DMS (linha) & \multicolumn{4}{|c|}{23,18} \\
\hline DMS (coluna) & \multicolumn{4}{|c|}{24,35} \\
\hline
\end{tabular}

${ }^{1 /}$ Com base no teste de Tukey a $5 \%$ de probabilidade, médias seguidas de letra minúscula, nas colunas, comparam os tratamentos da época úmida dentro de cada manejo na época seca, e letras maiúsculas, nas linhas, comparam os quatro manejos na seca para cada tratamento da época úmida. ${ }^{2 /}$ Testemunha capinada apenas no dia da pulverização dos herbicidas na época úmida. 
Aos $91 \mathrm{DAA}_{\mathrm{HU}}$, quando foi pulverizado amicarbazone na seca, as maiores porcentagens de controle de $M$. aegyptia foram constatadas com a complementação de mesotrione + atrazine, mesotrione + metribuzin ou mesotrione + (diuron + hexazinone) na época úmida, com nota média de $86,88 \%$ (Tabela 6). Para clomazone + hexazinone houve melhor combinação de manejo com a aplicação de mesotrione + atrazine $(81,25 \%)$. O mesmo ocorreu para imazapic quando foi aplicado mesotrione + metribuzin ou mesotrione + (diuron + hexazinone), com 78,75\% de média. No tratamento sem aplicação de herbicida na seca, a melhor alternativa de manejo estudada na época úmida foi mesotrione + (diuron + hexazinone), com $61,25 \%$ de controle. Na testemunha sem manejo na época úmida, como nas avaliações anteriores, houve maior porcentagem de controle com a aplicação de amicarbazone na seca, porém o controle avaliado foi de apenas $41,25 \%$.

Em condições de vasos com $5 \mathrm{t} \mathrm{ha}^{-1}$ de palha de cana sobre o solo e simulação de $30 \mathrm{~mm}$ de chuva 24 horas após a pulverização, Toledo et al. (2009) mencionaram que o amicarbazone aplicado em pré-emergência foi eficaz no controle de Merremia cissoides, independentemente da dose avaliada $(0,525$; 0,$700 ; 0,875$; e $\left.1,050 \mathrm{~kg} \mathrm{ha}^{-1}\right)$. Em estudo similar, o herbicida oxyfluorfen também foi eficaz no controle dessa espécie (Negrisoli et al., 2009). Esses resultados demonstraram o potencial desses herbicidas no controle de $M$. cissoides numa situação de umidade adequada no solo. No presente trabalho, o amicarbazone também proporcionou controle adequado de $M$. aegyptia; no entanto, a sua concentração no solo não foi suficiente para evitar infestações tardias da planta daninha (a partir dos 143 dias da aplicação) e impedir possivel interferência na colheita mecanizada da cana.

Na última época de avaliação (120 DAA $\mathrm{HU}_{\mathrm{HU}}$ ), aos 233 dias após o corte da cana, a combinação de amicarbazone com as misturas de mesotrione com atrazine, metribuzin ou diuron + hexazinone, aplicados na época úmida, foi eficaz no controle de $M$. aegyptia (média de $88,75 \%$ ) (Tabela 7). Para clomazone + hexazinone, as maiores notas foram obtidas com as associações de mesotrione ao atrazine ou ao metribuzin (média de 77,50\%). O mesmo foi observado para imazapic quando foi aplicado mesotrione + metribuzin ou mesotrione + (diuron + hexazinone) na época úmida (média de $79,50 \%$ ). Sem o manejo prévio das plantas daninhas na época seca, não houve diferença entre os tratamentos com herbicidas e as testemunhas (capinada e sem manejo). Isso confirma que, sem o manejo prévio das plantas daninhas na época seca, o uso de herbicidas na época úmida não foi suficiente para o controle adequado da planta daninha. O mesmo foi constatado sem o manejo químico na época úmida, pois os herbicidas clomazone + hexazinone e imazapic não diferiram do tratamento sem herbicida na época seca; e o amicarbazone, embora tenha diferido, proporcionou controle de apenas $41,25 \%$.

Monquero et al. (2009) relataram que a aplicação de mesotrione (192 $\mathrm{g} \mathrm{ha}^{-1}$ ) em plantas de Ipomoea grandifolia com seis folhas definitivas resultou em $100 \%$ de controle. O mesmo ocorreu com a sua associação aos herbicidas ametryn $\left(120+1.500 \mathrm{~g} \mathrm{ha}^{-1}\right)$ ou trifloxysulfuron + ametryn $[120+(27,770+$ 1,097) $\mathrm{g} \mathrm{ha}^{-1}$. Nesse estudo, sem o manejo químico na época seca, o mesotrione não foi eficaz no controle de $M$. aegyptia quando pulverizado em plantas de até oito folhas, com média de $77,50 \%$ aos 15 DAA. No entanto, a sua associação aos herbicidas atrazine, metribuzin ou diuron + hexazinone proporcionou excelente controle das plantas: acima de $98,75 \%$ aos 15 DAA. Posteriormente, tanto para o mesotrione isolado como em mistura, as notas foram decrescendo, devido à emergência de novas plantas de $M$. aegyptia na área.

Em canavial localizado no estado de Louisiana, EUA, Jones \& Griffin (2008) observaram que os herbicidas atrazine $\left(3,36 \mathrm{~kg} \mathrm{ha}^{-1}\right)$ e diuron + hexazinone $(2,10+$ $\left.0,59 \mathrm{~kg} \mathrm{ha}^{-1}\right)$, quando pulverizados em plantas adultas de Ipomoea coccinea (com 30 a $60 \mathrm{~cm}$ de altura), ocasionaram 92 e $97 \%$ de controle, respectivamente. Em pré-emergência, os herbicidas resultaram em controle inicial (aos 35 DAA) acima de $90 \%$. Contudo, as notas decresceram para menos de $50 \%$ aos 77 DAA, em virtude da emergência de novas plantas nas parcelas. Segundo esses autores, o herbicida atrazine é amplamente utilizado no controle em pré-emergência de $I$. coccinea na 
cultura da cana-de-açúcar no estado de Louisiana (EUA), porém o seu posicionamento em pós-emergência promoveria melhor aproveitamento do residual de controle desse herbicida (Jones \& Griffin, 2008), desde que respeitado o período crítico de prevenção da interferência. A esse respeito, herbicidas totalmente seletivos às plantas de cana, como mesotrione, atrazine e metribuzin, poderiam ser aplicados em pós-emergência em jato dirigido e também sobre a cultura, se não houvesse prejuízos por efeito "guarda-chuva" (Azania et al., 2006; Jones \& Griffin, 2008; Monquero et al., 2009).

Quanto ao potencial de reinfestação da área experimental, avaliado após a aplicação dos herbicidas na época úmida, a interação entre os manejos foi significativa apenas aos $15 \mathrm{DAA}_{\mathrm{HU}}$. Para os fatores isolados, houve efeito significativo dos herbicidas pulverizados na época úmida no número de plantas de M. aegyptia aos 15, 30, 45 e $62 \mathrm{DAA}_{\mathrm{HU}}$, ao contrário dos manejos avaliados na seca, que não foram significativos para nenhuma época de avaliação.

Aos $15 \mathrm{DAA}_{\mathrm{HU}}$, para amicarbazone e clomazone + hexazinone não houve diferença significativa entre os manejos adotados na época úmida, com média de 0,31 planta $\mathrm{m}^{-2}$ (Tabela 8). Nas parcelas pulverizadas com imazapic, a aplicação de mesotrione isolado resultou em maior número de plantas

Tabela 6 - Porcentagem de controle de Merremia aegyptia aos 91 dias após a aplicação de herbicidas na época úmida. Pradópolis-SP. 2008/2009

\begin{tabular}{|c|c|c|c|c|}
\hline \multirow[b]{2}{*}{ Manejo na época úmida } & \multicolumn{4}{|c|}{ Manejo na época seca } \\
\hline & amicarbazone & $\begin{array}{l}\text { clomazone }+ \\
\text { hexazinone }\end{array}$ & imazapic & $\begin{array}{l}\text { Tratamento sem } \\
\text { herbicida }\end{array}$ \\
\hline mesotrione & $73,75 \mathrm{ab} \mathrm{A}^{1 /}$ & $51,25 \mathrm{abc} A B$ & $35,00 \mathrm{bc} \mathrm{B}$ & $17,50 \mathrm{~b} \quad \mathrm{~B}$ \\
\hline mesotrione + atrazine & $91,25 \mathrm{a} \mathrm{A}$ & $81,25 \mathrm{a} \quad \mathrm{A}$ & $62,50 \mathrm{ab} A$ & $27,50 \mathrm{ab} B$ \\
\hline mesotrione + metribuzin & 82,50 a $\mathrm{A}$ & $78,50 \mathrm{ab} \quad \mathrm{A}$ & 78,75 a $\mathrm{A}$ & $22,50 \mathrm{~b} \quad \mathrm{~B}$ \\
\hline mes.+(diuron+hexazinone) & $91,25 \mathrm{a} \mathrm{A}$ & $65,00 \mathrm{ab} \quad \mathrm{A}$ & $78,75 \mathrm{a} \mathrm{A}$ & $61,25 \mathrm{a} \mathrm{A}$ \\
\hline Testemunha capinada $^{2 / /}$ & 80,00 a $\mathrm{A}$ & $43,75 \mathrm{bc} B$ & $38,75 \mathrm{~b} \quad \mathrm{~B}$ & $16,25 \mathrm{~b} \quad \mathrm{~B}$ \\
\hline Testemunha sem manejo & $41,25 \mathrm{~b} \quad \mathrm{~A}$ & $22,50 \mathrm{c} \quad \mathrm{AB}$ & $0,00 \mathrm{c} \quad \mathrm{B}$ & $0,00 \mathrm{~b} \quad \mathrm{~B}$ \\
\hline DMS (linha) & \multicolumn{4}{|c|}{34,46} \\
\hline DMS (coluna) & \multicolumn{4}{|c|}{37,28} \\
\hline
\end{tabular}

${ }_{1 /}$ Com base no teste de Tukey a 5\% de probabilidade, médias seguidas de letra minúscula, nas colunas, comparam os tratamentos da época úmida dentro de cada manejo na época seca, e letras maiúsculas, nas linhas, comparam os quatro manejos na seca para cada tratamento da

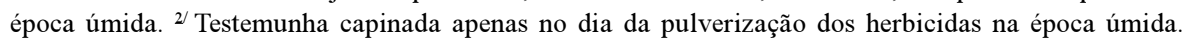

Tabela 7 - Porcentagem de controle de Merremia aegyptia aos 120 dias após a aplicação de herbicidas na época úmida. Pradópolis-SP. 2008/2009

\begin{tabular}{|c|c|c|c|c|}
\hline \multirow[b]{2}{*}{ Manejo na época úmida } & \multicolumn{4}{|c|}{ Manejo na época seca } \\
\hline & amicarbazone & $\begin{array}{l}\text { clomazone }+ \\
\text { hexazinone }\end{array}$ & imazapic & $\begin{array}{l}\text { Tratamento sem } \\
\text { herbicida }\end{array}$ \\
\hline mesotrione & $76,25 \mathrm{ab} \mathrm{A}^{\frac{1}{1}}$ & $45,00 \mathrm{ab} \mathrm{AB}$ & 20,00 c B & $12,50 \mathrm{a} \mathrm{B}$ \\
\hline mesotrione + atrazine & $91,25 \mathrm{a} \quad \mathrm{A}$ & $77,50 \mathrm{a} \quad \mathrm{A}$ & $62,50 \mathrm{ab} A$ & 22,50 a B \\
\hline mesotrione + metribuzin & 82,50 a $\mathrm{A}$ & $77,50 \mathrm{a} \quad \mathrm{A}$ & 77,50 a $\mathrm{A}$ & 23,75 a B \\
\hline mes.+(diuron+hexazinone $)$ & $92,50 \mathrm{a} A$ & $50,00 \mathrm{ab} \mathrm{BC}$ & 81,50 a $\mathrm{AB}$ & 32,50 a C \\
\hline Testemunha capinada ${ }^{2 /}$ & 81,25 a $\mathrm{A}$ & $42,50 \mathrm{ab} B$ & 28,75 bc B & 16,25 a B \\
\hline Testemunha sem manejo & $41,25 \mathrm{~b} \quad \mathrm{~A}$ & $20,00 \mathrm{~b} \quad \mathrm{AB}$ & $0,00 \mathrm{c} B$ & $0,00 \mathrm{a} \mathrm{B}$ \\
\hline DMS (linha) & \multicolumn{4}{|c|}{36,26} \\
\hline DMS (coluna) & \multicolumn{4}{|c|}{36,24} \\
\hline
\end{tabular}

1/ Com base no teste de Tukey a 5\% de probabilidade, médias seguidas de letra minúscula, nas colunas, comparam os tratamentos da época úmida dentro de cada manejo na época seca, e letras maiúsculas, nas linhas, comparam os quatro manejos na seca para cada tratamento da época úmida. ${ }^{2 /}$ Testemunha capinada apenas no dia da pulverização dos herbicidas na época úmida. 
Tabela 8 - Número de plantas (por $\mathrm{m}^{2}$ ) de Merremia aegyptia emergidas aos 15 dias após a aplicação de herbicidas na época úmida. Pradópolis-SP. 2008/2009

\begin{tabular}{|c|c|c|c|c|}
\hline \multirow[b]{2}{*}{ Manejo na época úmida } & \multicolumn{4}{|c|}{ Manejo na época seca } \\
\hline & amicarbazone & $\begin{array}{l}\text { clomazone }+ \\
\text { hexazinone }\end{array}$ & imazapic & $\begin{array}{c}\text { Tratamento sem } \\
\text { herbicida }\end{array}$ \\
\hline mesotrione & $0,25 \mathrm{a} \mathrm{A}^{\mathrm{1}^{\prime}}$ & 0,89 a $\mathrm{AB}$ & $1,76 \mathrm{~b} \mathrm{~B}$ & 0,99 a $\mathrm{AB}$ \\
\hline mesotrione + atrazine & 0,07 a $A$ & 0,04 a $A$ & 0,29 a A & 0,44 a $A$ \\
\hline mesotrione + metribuzin & $0,24 \mathrm{a} \mathrm{A}$ & $0,22 \mathrm{a} \mathrm{A}$ & 0,33 a A & 0,31 a A \\
\hline mes.+(diuron+hexazinone) & 0,18 a $A$ & 0,22 a $\mathrm{A}$ & 0,22 a $A$ & 0,33 a $\mathrm{A}$ \\
\hline Testemunha capinada ${ }^{2 /}$ & 0,47 a $\mathrm{A}$ & 0,49 a A & $1,29 \mathrm{~b} \mathrm{~A}$ & $2,36 \mathrm{~b} \mathrm{~B}$ \\
\hline DMS (linha) & \multicolumn{4}{|c|}{1,01} \\
\hline DMS (coluna) & \multicolumn{4}{|c|}{0,95} \\
\hline
\end{tabular}

1/ Com base no teste de Tukey a $5 \%$ de probabilidade, médias seguidas de letra minúscula, nas colunas, comparam os tratamentos da época úmida dentro de cada manejo na época seca, e letras maiúsculas, nas linhas, comparam os quatro manejos na seca para cada tratamento da época úmida. ${ }^{2}$ Testemunha capinada apenas no dia da pulverização dos herbicidas na época úmida.

$\left(1,76\right.$ planta $\left.\mathrm{m}^{-2}\right)$, diferindo das suas associações com atrazine $\left(0,29\right.$ planta $\left.\mathrm{m}^{-2}\right)$, metribuzin $\left(0,33\right.$ planta $\left.\mathrm{m}^{-2}\right)$ ou diuron + hexazinone $\left(0,22\right.$ planta $\left.\mathrm{m}^{-2}\right)$. Para o tratamento sem manejo químico na época seca, os tratamentos com herbicidas não diferiram entre si. Na testemunha com eliminação manual das plantas de $M$. aegyptia no momento da segunda aplicação, houve maior número de plantas no tratamento sem herbicida na seca $\left(2,36\right.$ plantas $\left.\mathrm{m}^{-2}\right)$, diferindo de amicarbazone $\left(0,47\right.$ planta $\left.\mathrm{m}^{-2}\right)$, clomazone + hexazinone $\left(0,49\right.$ planta $\left.\mathrm{m}^{-2}\right)$ e imazapic $\left(1,29\right.$ plantas $\left.\mathrm{m}^{-2}\right)$.

Aos $30 \mathrm{DAA}_{\mathrm{HU}}$, independentemente do manejo adotado na época seca, verificou-se menor número de plantas de $M$. aegyptia com a aplicação de mesotrione + atrazine e mesotrione + metribuzin, não diferindo de mesotrione $+($ diuron + hexazinone) (Tabela 9). O mesmo foi observado aos $45 \mathrm{DAA}_{\mathrm{HU}}$, em que misturas resultaram em menor emergência de $M$. aegyptia, diferindo significativamente de mesotrione isolado. No entanto, aos $60 \mathrm{DAA}_{\mathrm{HU}}$ não houve diferença significativa entre os tratamentos estudados. Para todas as épocas de avaliação, os tratamentos da época seca não diferiram entre si, com média de 4,78; 4,04; 3,63 e 2,71 plantas $\mathrm{m}^{-2}$, respectivamente para o tratamento sem herbicida, clomazone + hexazinone, imazapic e amicarbazone.

Quanto às características avaliadas nas plantas de cana, as aplicações do mesotrione, isolado e em mistura com atrazine, metribuzin ou diuron + hexazinone, resultaram em injúrias visuais classificadas como nulas ou muito leves $(1,88$ a $5,94 \%)$, as quais desapareceram aos 15 DAA (dados não apresentados). As combinações dos manejos adotados nas épocas seca e úmida não afetaram o crescimento da cana-de-açúcar, ao contrário do tratamento mantido infestado durante todo o período experimental, em que as plantas apresentaram menor altura, diâmetro de colmos e número de colmos por metro linear (Tabelas 10, $11 \mathrm{e}$ 12). Silva et al. (2009) constataram que o canavial (variedade RB 85-5536) mantido sem plantas daninhas durante todo o ciclo produziu 10,68 colmos por metro. Já o canavial em convivência com a comunidade infestante (composta principalmente por I. hederifolia) até os 229 dias após a brotação apresentou 7,06 colmos por metro, correspondendo a uma

Tabela 9 - Número de plantas (por $\mathrm{m}^{2}$ ) de Merremia aegyptia emergidas aos 15, 30, 45 e 62 dias após a aplicação de herbicidas na época úmida, além da testemunha capinada apenas no dia da pulverização. Pradópolis-SP. 2008/2009

\begin{tabular}{|l|c|c|c|c|}
\hline \multirow{2}{*}{ Manejo na época úmida } & \multicolumn{4}{|c|}{ Dias após a aplicação } \\
\cline { 2 - 5 } & 15 & 30 & 45 & 62 \\
\hline mesotrione & $0,97 \mathrm{~b}^{\mathbf{1}}$ & $2,12 \mathrm{c}$ & $4,35 \mathrm{~b}$ & $4,30 \mathrm{a}$ \\
\hline mesotrione + atrazine & $0,21 \mathrm{a}$ & $0,99 \mathrm{a}$ & $2,64 \mathrm{a}$ & $3,38 \mathrm{a}$ \\
\hline mesotrione + metribuzin & $0,28 \mathrm{a}$ & $0,94 \mathrm{a}$ & $2,71 \mathrm{a}$ & $3,70 \mathrm{a}$ \\
\hline mes.+(diuron+hexazinone) & $0,24 \mathrm{a}$ & $1,09 \mathrm{ab}$ & $2,91 \mathrm{a}$ & $3,75 \mathrm{a}$ \\
\hline Testemunha capinada & $1,15 \mathrm{~b}$ & $1,94 \mathrm{bc}$ & $3,08 \mathrm{ab}$ & $3,80 \mathrm{a}$ \\
\hline DMS & 0,47 & 0,91 & 1,44 & 1,79 \\
\hline
\end{tabular}

${ }^{1 /}$ Médias seguidas da mesma letra na coluna não diferem significativamente entre si pelo teste de Tukey a $5 \%$ de probabilidade. 
Tabela 10 - Diâmetro médio de colmos (mm) de cana aos 198 dias após a aplicação de herbicidas na época úmida (313 dias após a colheita). Pradópolis-SP. 2008/2009

\begin{tabular}{|c|c|c|c|c|}
\hline \multirow[b]{2}{*}{ Manejo na época úmida } & \multicolumn{4}{|c|}{ Manejo na época seca } \\
\hline & amicarbazone & $\begin{array}{l}\text { clomazone + } \\
\text { hexazinone }\end{array}$ & imazapic & $\begin{array}{c}\text { Tratamento sem } \\
\text { herbicida }\end{array}$ \\
\hline mesotrione & 23,23 & 23,50 & 20,97 & $25,00 \mathrm{a}^{1 /}$ \\
\hline mesotrione + atrazine & 23,17 & 23,37 & 22,87 & $23,60 \mathrm{a}$ \\
\hline mesotrione + metribuzin & 24,40 & 22,39 & 23,40 & $24,27 \mathrm{a}$ \\
\hline mes.+(diuron+hexazinone) & 23,57 & 22,60 & 24,47 & $23,03 \mathrm{a}$ \\
\hline Testemunha capinada $^{2 /}$ & 23,83 & 24,91 & 23,68 & $23,47 \mathrm{a}$ \\
\hline Testemunha sem manejo & $22,48 \mathrm{~A}$ & $23,09 \mathrm{~A}$ & $22,38 \mathrm{~A}$ & $6,73 \mathrm{bB}$ \\
\hline DMS (linha) & \multicolumn{4}{|c|}{5,92} \\
\hline DMS (coluna) & \multicolumn{4}{|c|}{6,62} \\
\hline
\end{tabular}

${ }^{1 /}$ Com base no teste de Tukey a $5 \%$ de probabilidade, médias seguidas de letra minúscula, nas colunas, comparam os tratamentos da época úmida dentro de cada manejo na época seca, e letras maiúsculas, nas linhas, comparam os quatro manejos na seca para cada tratamento da época úmida. ${ }^{2 /}$ Testemunha capinada apenas no dia da pulverização dos herbicidas na época úmida.

Tabela 11 -Altura média de colmos (cm) de cana aos 198 dias após a aplicação de herbicidas na época úmida (313 dias após a colheita) Pradópolis-SP. 2008/2009

\begin{tabular}{|c|c|c|c|c|}
\hline \multirow[b]{2}{*}{ Manejo na época úmida } & \multicolumn{4}{|c|}{ Manejo na época seca } \\
\hline & amicarbazone & $\begin{array}{l}\text { clomazone }+ \\
\text { hexazinone }\end{array}$ & imazapic & $\begin{array}{c}\text { Tratamento sem } \\
\text { herbicida }\end{array}$ \\
\hline mesotrione & 198,66 & 198,03 & 200,13 & $177,00 \mathrm{a}^{\mathrm{1}^{\prime}}$ \\
\hline mesotrione + atrazine & 200,97 & 197,87 & 194,23 & $177,92 \mathrm{a}$ \\
\hline mesotrione + metribuzin & 199,20 & 204,57 & 188,93 & $193,93 \mathrm{a}$ \\
\hline mes.+(diuron+hexazinone) & 202,53 & 197,53 & 189,33 & $202,13 \mathrm{a}$ \\
\hline Testemunha capinada $^{2 / /}$ & 206,07 & 189,57 & 189,40 & $179,43 \mathrm{a}$ \\
\hline Testemunha sem manejo & $203,73 \mathrm{~A}$ & $178,40 \mathrm{~A}$ & $160,43 \mathrm{~A}$ & $61,73 \mathrm{~b} \mathrm{~B}$ \\
\hline DMS (linha) & \multicolumn{4}{|c|}{53,86} \\
\hline DMS (coluna) & \multicolumn{4}{|c|}{58,74} \\
\hline
\end{tabular}

${ }^{1 /}$ Com base no teste de Tukey a 5\% de probabilidade, médias seguidas de letra minúscula, nas colunas, comparam os tratamentos da época úmida dentro de cada manejo na época seca, e letras maiúsculas, nas linhas, comparam os quatro manejos na seca para cada tratamento da época úmida. ${ }^{2 /}$ Testemunha capinada apenas no dia da pulverização dos herbicidas na época úmida.

Tabela 12 - Número médio de colmos de cana por metro linear aos 198 dias após a aplicação de herbicidas na época úmida (313 dias após a colheita). Pradópolis-SP. 2008/2009

\begin{tabular}{|c|c|c|c|c|}
\hline \multirow[b]{2}{*}{ Manejo na época úmida } & \multicolumn{4}{|c|}{ Manejo na época seca } \\
\hline & amicarbazone & $\begin{array}{l}\text { clomazone }+ \\
\text { hexazinone }\end{array}$ & imazapic & $\begin{array}{c}\text { Tratamento sem } \\
\text { herbicida }\end{array}$ \\
\hline mesotrione & 10,33 & 10,00 & 10,00 & $10,00 \mathrm{a}^{\frac{1 /}{}}$ \\
\hline mesotrione + atrazine & 12,00 & 11,67 & 8,92 & $9,00 \mathrm{a}$ \\
\hline mesotrione + metribuzin & 10,75 & 10,08 & 10,00 & $11,42 \mathrm{a}$ \\
\hline mes.+(diuron+hexazinone) & 10,00 & 12,17 & 9,92 & $11,67 \mathrm{a}$ \\
\hline Testemunha capinada $^{2 / /}$ & 10,58 & 9,92 & 11,33 & $10,83 \mathrm{a}$ \\
\hline Testemunha sem manejo & $10,08 \mathrm{~A}$ & $10,42 \mathrm{~A}$ & $9,92 \mathrm{~A}$ & $2,17 \mathrm{~b} \mathrm{~B}$ \\
\hline DMS (linha) & \multicolumn{4}{|c|}{4,61} \\
\hline DMS (coluna) & \multicolumn{4}{|c|}{5,16} \\
\hline
\end{tabular}

1/ Com base no teste de Tukey a 5\% de probabilidade, médias seguidas de letra minúscula, nas colunas, comparam os tratamentos da época úmida dentro de cada manejo na época seca, e letras maiúsculas, nas linhas, comparam os quatro manejos na seca para cada tratamento da época úmida. ${ }^{2 /}$ Testemunha capinada apenas no dia da pulverização dos herbicidas na época úmida. 
redução de 34\%. A espécie $M$. aegyptia mostrou-se ainda mais competitiva, pois nesta pesquisa a convivência dessa espécie durante todo o ciclo da cana resultou em apenas 2,17 colmos por metro - $80 \%$ a menos do que a testemunha com a eliminação manual das plantas daninhas na época úmida, que apresentou média de 10,83 colmos por metro (Tabela 12).

A densidade e a altura das plantas de M. aegyptia no momento da segunda aplicação influenciaram na eficácia dos herbicidas pulverizados na época úmida e também indicaram a redução na concentração no solo dos herbicidas aplicados na época seca, devido aos novos fluxos de emergência da planta daninha nas parcelas, o que foi mais acentuado nas parcelas de imazapic e clomazone + hexazinone.

A pressão da planta daninha na área experimental foi considerada muito alta, seja pelo seu crescimento rápido e pronunciada ramificação, seja pela ocorrência de fluxos contínuos de emergência na maioria dos manejos adotados. Isso corrobora a baixa capacidade competitiva da cana-de-açúcar (variedade SP 81-3250), que apresentou crescimento lento e falha de brotação em todos os tratamentos. Esse fato influenciou no fechamento do dossel das plantas e, consequentemente, no sombreamento da área e possivel manejo cultural da planta daninha.

No entanto, tendo-se como critério as características avaliadas na cana no momento da colheita (altura, diâmetro e número de colmos viáveis), o período compreendido entre a aplicação dos herbicidas na época úmida (ou a eliminação manual das plantas) e os 45 DAA, independentemente do uso de herbicidas na seca, foi suficiente para evitar possivel competição da planta daninha com a cultura de cana. Portanto, os tratamentos com os herbicidas utilizados foram eficazes em evitar a interferência de $M$. aegyptia no crescimento da cana-de-açúcar. No entanto, para espécies trepadeiras deve-se levar em consideração, além de prejuízos na capacidade produtiva da cultura, a possivel interferência na realização da colheita mecanizada. Quanto à dificuldade de realização da colheita mecanizada dos colmos de cana (Tabela 13), unicamente nas parcelas pulverizadas com amicarbazone na época seca e, necessariamente, complementadas na época úmida com as associações de mesotrione aos herbicidas atrazine, metribuzin ou diuron + hexazinone, não haveria impedimento à realização da colheita mecanizada. Para todos os outros tratamentos, haveria comprometimento da realização dessa operação.

Com base nos resultados, pode-se concluir que, entre os herbicidas utilizados na época seca, o amicarbazone resultou no melhor controle de $M$. aegyptia. No entanto, para todos eles, a complementação de manejo com a aplicação de herbicidas na época úmida mostrou-se obrigatória. Na época úmida, a associação de mesotrione aos herbicidas atrazine, metribuzin ou diuron + hexazinone foi mais eficaz no controle de $M$. aegyptia do que quando

Tabela 13 - Dificuldade de colheita mecanizada dos colmos de cana-de-açúcar aos 198 dias após a aplicação de herbicidas na época úmida (313 dias após a colheita). Pradópolis-SP. 2008/2009

\begin{tabular}{|l|c|c|c|c|}
\hline \multirow{2}{*}{\multicolumn{1}{c|}{ Manejo na época úmida }} & \multicolumn{4}{c|}{ Manejo na época seca } \\
\cline { 2 - 5 } & amicarbazone & $\begin{array}{c}\text { clomazone }+ \\
\text { hexazinone }\end{array}$ & imazapic & $\begin{array}{c}\text { Tratamento sem } \\
\text { herbicida }\end{array}$ \\
\hline mesotrione & 1,75 & 3,00 & 3,00 & 3,00 \\
\hline mesotrione + atrazine & 1,00 & 1,50 & 2,00 & 3,00 \\
\hline mesotrione + metribuzin & 1,00 & 1,75 & 1,75 & 3,00 \\
\hline mes.+(diuron+hexazinone) & 1,00 & 2,50 & 1,75 & 3,00 \\
\hline Testemunha capinada $2 /$ & 1,75 & 3,00 & 3,00 & 3,00 \\
\hline Testemunha sem manejo & 3,00 & 3,00 & 3,00 & 3,00 \\
\hline
\end{tabular}

1/ Escala de notas de 1 a 3 . As notas representam: 1 - colheita sem $M$. aegyptia ou com baixa infestação (sem causar impedimentos), 2 colheita com presença moderada de $M$. aegyptia e 3 - colheita com presença elevada de M. aegyptia. $\stackrel{2}{2}$ Testemunha capinada apenas no dia da pulverização dos herbicidas na época úmida. 
aplicado sozinho. Nenhum dos tratamentos com herbicidas interferiu no número de colmos por metro linear, diâmetro e altura de colmos de cana-de-açúcar (variedade SP 81-3250).

\section{LITERATURA CITADA}

SISTEMA DE AGROTÓXICOS FITOSSANITÁRIOS AGROFIT. Disponível em: <http://www. extranet. agricultura.gov.br/agrofit_cons/principal_agrofit_cons $>$. Acesso em: 31 ago. 2010

AZANIA, C. A. M. et al. Seletividade de herbicidas: III aplicação de herbicidas em pós-emergência inicial e tardia da cana-de-açúcar na época da estiagem. Planta Daninha, v. 24, n. 3, p. 489-495, 2006.

CORREIA, N. M;; DURIGAN, J. C. Emergência de plantas daninhas em solo coberto com palha de cana-de-açúcar. Planta Daninha, v. 22, n. 1, p. 11-17, 2004

JONES, C. A.; GRIFFIN, J. L. Residual red morningglory (Ipomoea coccinea) control with foliar- and soil-applied herbicides. Weed Technol., v. 22, n. 3, p. 402-407, 2008.

KISSMANN, K. G.; GROTH, D. Plantas infestantes e nocivas. 2.ed. São Paulo: BASF, 1999. 978 p. (Tomo II)

KUVA, M. A. et al. Fitossociologia de comunidades de plantas daninhas em agroecossistema cana-crua.

Planta Daninha, v. 25, n. 3, p. 501-511, 2007.
MONQUERO, P. A. et al. Eficácia de herbicidas aplicados em diferentes épocas e espécies daninhas em área de cana-deaçúcar colhida mecanicamente. Planta Daninha, v. 27, n. 2, p. $309-317,2009$.

NEGRISOLI, E. et al. Eficácia do herbicida oxyfluorfen com a cobertura de palha no controle de plantas daninhas.

Planta Daninha, v. 27, n. 1, p. 197-203, 2009.

PROCÓPIO, S. O.; SILVA, A. A.; VARGAS, L. Manejo e controle de plantas daninhas em cana-de-açúcar. In: VARGAS, L.; ROMAN, E. S. Manual de manejo e controle de plantas daninhas. Passo Fundo: Embrapa Trigo, 2008. $780 \mathrm{p}$

RODRIGUES, B. N.; ALMEIDA, F. L. S. Guia de herbicidas. 5.ed. Londrina: Edição dos Autores, 2005. 592 p.

SILVA, I. A. B. et al. Interferência de uma comunidade de plantas daninhas com predominância de Ipomoea hederifolia na cana-soca. Planta Daninha, v. 27, n. 2, p. 265-272, 2009.

SOCIEDADE BRASILEIRA DA CIENNCIA DAS PLANTAS DANINHAS - SBCPD. Procedimentos para instalação, avaliação e análise de experimentos com herbicidas. Londrina: 1995. 42 p.

TOLEDO, R. E. B. et al. Eficácia do herbicida amicarbazone aplicado sobre a palha ou no solo no controle de plantas daninhas na cultura da cana-de-açúcar. Planta Daninha, v. 27, n. 2 , p. $319-326,2009$. 